\title{
Single nucleotide polymorphisms of SCN5A and SCN10A genes increase the risk of ventricular arrhythmias during myocardial infarction
}

\author{
Hajer Foddha ${ }^{1,2, A-D, F}$, Nadia Bouzidi', , Abdelhak Foddha ${ }^{3, A-C}$, Saoussen Chouchene ${ }^{4, B}$, Rahma Touhamii ${ }^{1,2, B}$, Nadia Leban ${ }^{1, E}$, \\ Mohamed Faouzi Maatoug ${ }^{3, B}$, Habib Gamra ${ }^{3, B}$, Salima Ferchichi', , Jemni Ben Chibani ${ }^{1}, \mathrm{E}$, Amel Haj Khelil ${ }^{1,2, C-F}$ \\ ${ }^{1}$ Laboratory of Biochemistry and Molecular Biology, Faculty of Pharmacy, University of Monastir, Tunisia \\ ${ }^{2}$ Higher Institute of Biotechnology, University of Monastir, Tunisia \\ ${ }^{3}$ Department of Cardiology, Fattouma Bourguiba University Hospital of Monastir, Tunisia \\ ${ }^{4}$ Department of Hematology, Fattouma Bourguiba University Hospital of Monastir, Tunisia \\ A - research concept and design; $\mathrm{B}$ - collection and/or assembly of data; $\mathrm{C}$ - data analysis and interpretation; \\ $D$ - writing the article; $E$ - critical revision of the article; $F$ - final approval of the article
}

\section{Address for correspondence}

Hajer Foddha

E-mail: hajer.foddha@hotmail.fr

\section{Funding sources}

None declared

Conflict of interest

None declared

Received on September 8, 2019

Reviewed on November 11, 2019

Accepted on January 21, 2020

Published online on April 24, 2020

\section{Cite as}

Foddha H, Bouzidi N, Foddha A, et al. Single nucleotide polymorphisms of SCN5A and SCN10A genes increase the risk of ventricular arrhythmias during myocardial infarction. Adv Clin Exp Med. 2020;29(4):423-429.

doi:10.17219/acem/116750

DOI

10.17219/acem/116750

Copyright

Copyright by Author(s)

This is an article distributed under the terms of the

Creative Commons Attribution 3.0 Unported (CC BY 3.0)

(https://creativecommons.org/licenses/by/3.0/)

\section{Abstract}

Background. Coronary artery disease (CAD) and its ultimate consequence - myocardial infarction (MI) - are major causes of sudden cardiac death (SCD). Previous studies have demonstrated the role of genetic polymorphisms in the risk of SCD and ventricular arrhythmia (VA) during MI.

Objectives. To investigate the association between single nucleotide polymorphisms (SNPs) of genes implicated in congenital cardiac arrhythmias and the risk of developing VA in the context of MI.

Material and methods. We performed a case-control study in which we genotyped 4 SNPs (rs11708996, rs10428132, rs9388451, and rs2200733) in 469 subjects using amplification refractory mutation system (ARMS) and a polymerase chain reaction-restriction fragment length polymorphism (PCR-RFLP). These SNPs are located in the SCN5A, SCN10A, HEY2, and PITX2 genes, respectively. We first compared 70 patients who had developed VA in the context of MI with 141 healthy controls; next, we compared VA patients with 258 MI patients who did not develop VA during a 1-year follow up. The statistical analyses were adjusted for sex and age.

Results. Compared to the controls, 2 polymorphisms were significantly associated with the development of VA during MI, located in SCN5A rs11708996 ( $p=0.001)$ and SCN10A rs10428132 ( $p=0.001)$. Similar results were found when comparing VA cases with patients without VA. No associations of HEY2 and PITX2 polymorphisms were observed.

Conclusions. Our results suggest that the rs11708996 and rs10428132 polymorphisms of the SCN5A and SCN10A genes may contribute to an elevated risk of developing VA in the context of MI. The associated alleles or genotypes may be used to predict the risk, and thus prevent eventual SCD.

Key words: single nucleotide polymorphism, myocardial infarction, ventricular arrhythmia, sudden cardiac death 


\section{Introduction}

In the last decade, there have been notable advances in the study of the mechanisms responsible for increased risk of arrhythmia and sudden cardiac death (SCD). In $5-10 \%$ of all cases, SCD occurs in patients with congenital rhythm disorders with normal heart structure. ${ }^{1}$ However, SCD is mainly described in the setting of structural heart disease resulting from ventricular arrhythmias (VA), particularly ventricular fibrillation (VF).

Ventricular arrhythmia most commonly occurs early in ischemia, and patients presenting acute myocardial infarction (MI) and VA show a high risk of mortality. ${ }^{2,3}$ In nearly $10 \%$ of cases, VA occurs within the first hours following the MI symptoms. ${ }^{4,5}$

Recognition of the genetic substrate underlying normal and abnormal electrical behavior in congenital arrhythmias has provided remarkable insight into the molecular basis of cardiac electrophysiology. The variants described may be of use in the general framework of all types of arrhythmias. It has been shown that some variants in the SCN5A gene can be considered a genetic risk for some acquired arrhythmias. The original causes can be heart failure, MI or coronary artery disease (CAD). ${ }^{6}$ The input of $S C N 5 A$ mutations under ischemic conditions has been examined. In fact, the first sodium channel mutation to be associated with the development of an arrhythmic event during acute ischemia (G400A) was discovered in a patient who developed 6 episodes of VA within the first $12 \mathrm{~h} .^{7}$

Brugada syndrome $(\mathrm{BrS})$ is a primary electrical heart disease with a high risk of VF and SCD. ${ }^{8}$ Some studies suggest that $\mathrm{BrS}$ and VA during $\mathrm{MI}$ are the result of a similar electrophysiological substrate, and sometimes the 2 diseases are confused. ${ }^{9,10}$ In this context, the genetic background of some congenital rhythm disorders could serve as a marker of arrhythmia in common cardiac diseases.
Single nucleotide polymorphisms (SNPs) that may play a role in high risk of VA and SCD diseases like atrial fibrillation $(\mathrm{AF})^{11}$ and $\mathrm{BrS}$ have been identified by genomewide association studies (GWAS) on the PITX2, ${ }^{12}$ SCN5A, $S C N 10 A$, and HEY2 genes. ${ }^{13}$ More recently, some of them have been involved in Brs, ${ }^{14}$ long QT syndrome and SCD. ${ }^{15}$

In this in mind, we designed a case-control study using 4. SNPs previously associated with BrS (rs11708996, rs10428132 and rs9388451) and AF (rs2200733) to test their influence on the physiopathology of cardiac arrhythmias in patients with structural heart disease, aiming at finding a genetic marker that could be used as a general predictor of SCD.

\section{Material and methods}

\section{Features of the populations studied}

We enrolled a sample of patients with MI who developed VA $\left(\mathrm{VA}^{+}\right)$and compared them to a group of controls. The definition of MI is based on the European Society of Cardiology (ESC) 2018 diagnostic criteria ${ }^{16}$ and was diagnosed using coronary angiogram. Ventricular arrhythmia is defined as the presence of documented ventricular tachycardia (VT) or VF after AMI. The VA can be sustained VT/VF when its lasts more than $30 \mathrm{~s}$ of consecutive beats, or non-sustained VT/VF, defined as more than 5 consecutive beats lasting below $30 \mathrm{~s}$, or VT/VF that must be terminated by immediate defibrillation due to hemodynamic instability. Over a follow-up period of 1 year, we also included patients who died from SCD of presumed arrhythmic origin.

A total of 481 unrelated Tunisian patients were admitted to the Department of Cardiology at the University Hospital of Monastir (Tunisia) for a suspected MI between October 2014 and June 2015. For this study, we considered

Table 1. Amplification conditions for SNP genotyping

\begin{tabular}{|c|c|c|c|c|}
\hline SNP & Primers & Type of PCR & PCR conditions & $\begin{array}{l}\text { Fragment length } \\
(\mathrm{bp})\end{array}$ \\
\hline rs2200733 & $\begin{array}{l}\text { F: 5'GCCTGCTTGGGTGGATGAAT3' } \\
\text { R: 5'CCCAGAGGCTCTATGGGATG3' }\end{array}$ & RFLP-PCR & $\begin{array}{l}94^{\circ} \mathrm{C} \text { for } 10 \mathrm{~min}, \\
35 \mathrm{cycles} \text { of: } \\
-94^{\circ} \mathrm{C} \text { for } 30 \mathrm{~s} \text {, } \\
-60^{\circ} \mathrm{C} \text { for } 30 \mathrm{~s}, \\
-72^{\circ} \mathrm{C} \text { for } 1 \mathrm{~min} \\
72^{\circ} \mathrm{C} \text { for } 10 \mathrm{~min}\end{array}$ & $\begin{array}{c}\text { CC: } 415+246 \\
\text { C/T: } 661+415+246 \\
\text { T/T: } 661\end{array}$ \\
\hline rs11708996 & 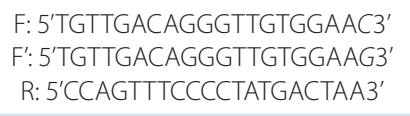 & \multirow{3}{*}{ ARMS-PCR } & \multirow{3}{*}{$\begin{array}{l}94^{\circ} \mathrm{C} \text { for } 10 \mathrm{~min}, \\
35 \mathrm{cycles} \text { of: } \\
-94^{\circ} \mathrm{C} \text { for } 30 \mathrm{~s}, \\
-55^{\circ} \mathrm{C} \text { for } 30 \mathrm{~s}, \\
-72^{\circ} \mathrm{C} \text { for } 1 \mathrm{~min} \\
72^{\circ} \mathrm{C} \text { for } 10 \mathrm{~min}\end{array}$} & 235 \\
\hline rs10428132 & $\begin{array}{l}\text { F: 5'TTAGCTCACTTATTCTCAAA3' } \\
\text { F': 5'TTAGCTCACTTATTCTCAAC3' } \\
\text { R: 5'GAGGAGAAGCAATGCTATTT3' }\end{array}$ & & & 328 \\
\hline rs9388451 & 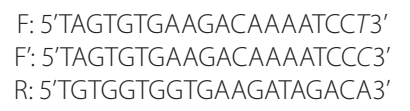 & & & 400 \\
\hline
\end{tabular}

SNP - single nucleotide polymorphism; PCR - polymerase chain reaction; ARMS-PCR - amplification refractory mutation system PCR; RFLP-PCR - restriction fragment length polymorphism PCR. 
those with confirmed diagnoses of MI $(n=328)$ and, in this group, those who developed VA during a follow-up period of 1 year $(n=70)$. In order to reinforce our study, we compared the $\mathrm{VA}^{+}$group to a sample of MI patients with no history of arrhythmic events $\left(\mathrm{VA}^{-} ; \mathrm{n}=258\right)$. Informed consent was obtained from all the patients included in the study. In the control cohort, 141 volunteer blood donors were recruited from the Blood Bank at the University Hospital of Mahdia (Tunisia). Inclusion criteria restricted the control group to those with no history of congenital or acquired cardiac arrhythmia and no family history of SCD.

\section{SNP genotyping}

Genomic DNA was extracted in all subjects from peripheral blood leukocytes using standard protocols. The SNPs associated with BrS (rs11708996, rs10428132 and rs9388451) were genotyped using a polymerase chain reactionrestriction fragment length polymorphism (PCR-RFLP). The one associated with AF (rs2200733) was genotyped using MboI restriction fragment length polymorphism (RFLP) PCR. All the details of the amplification conditions are summarized in Table 1.

\section{Statistical analysis}

Data distribution was checked with the Kolmogorov -Smirnov normality test. Parameters with normal distribution were presented as means \pm standard deviation (SD), and compared using Student's t-test. If there were more than 2 groups, the analysis of variance (ANOVA) procedure was followed by post-hoc tests. Parameters that showed nonnormal distribution were presented as median ( $\min -\max$ ); comparisons of more than 2 groups were done using one-way
ANOVA (Kruskal-Wallis test) followed by the Mann-Whitney U test. Categorical data was summarized as frequencies or percentages and compared in cross tables using Pearson's $\chi^{2}$ test. The IBM SPSS Statistics for Windows v. 22 software (IBM Corp., Armonk, USA) was used for all these tests.

Allelic distributions were compared using two-sided independent-sample Student's t-tests using Epi Info v. 1.4.3 software (Centers for Disease Control and Prevention, Atlanta, USA). Genotype frequencies between the case group and the control group were compared using the $X^{2}$ test. The $\chi^{2}$ goodness-of-fit test was employed to identify whether the genotype distributions fulfilled the Hardy -Weinberg equilibrium. Crude and adjusted genotyping associations in codominant, dominant and recessive models were analyzed with logistic regression analysis. These tests were assessed using SNPStats online software (https://bioinfo.iconcologia.net/SNPstats). ${ }^{17}$

Results with a p-value $<0.05$ were considered statistically significant. The relative risk was presented as odds ratios (OR) with 95\% confidence intervals (95\% CI).

\section{Results}

\section{Clinical features of the study populations}

The clinical history and demographic characteristics of the patients and controls are summarized in Table 2. The age and sex ratios were significantly different between the $\mathrm{VA}^{+}$patients and the controls $(\mathrm{p}<0.001)$. Myocardial infarction seems to occur more often in smoking men at advanced age. No significant differences were found between the patient groups in terms of age or gender. The MI patients with ST elevation (STEMI) were more likely

Table 2. Clinical history and demographic characteristics of the patients and controls

\begin{tabular}{|c|c|c|c|c|}
\hline \multirow{2}{*}{ Characteristics } & \multirow{2}{*}{ Controls (114) } & \multicolumn{2}{|c|}{ MI patients $(328)$} & \multirow{2}{*}{$\mathrm{p}$-value } \\
\hline & & $\mathrm{VA}^{-}(258)$ & $\mathrm{VA}^{+}(70)$ & \\
\hline Age [years] & $\begin{array}{c}44 \\
(21-76)\end{array}$ & $\begin{array}{c}57 \\
(31-88)\end{array}$ & $\begin{array}{c}54 \\
(27-83)\end{array}$ & $\begin{array}{c}<0.001^{a *} \\
0.075^{b}\end{array}$ \\
\hline Gender (male \%) & 42.5 & 80.6 & 90 & $\begin{array}{c}<0.001^{a *} \\
0.066^{b}\end{array}$ \\
\hline Smokers (\%) & 8.9 & 55.4 & 40 & $\begin{array}{l}<0.001^{a *} \\
0.047^{b *}\end{array}$ \\
\hline Personal history of VA (\%) & 0 & 0 & 15.1 & ns \\
\hline Victims of SCD (\%) & 0 & 0 & 34.2 & ns \\
\hline Family history of SCD (\%) & 0 & 4.6 & 11.1 & $0.036^{b *}$ \\
\hline ST-elevation myocardial infarction (\%) & 0 & 40.8 & 71.4 & $<0.001^{\text {b* }}$ \\
\hline Peak troponin I levels [ng/mL] & 0.00 & $\begin{array}{c}0.86 \\
(0.00-483.9)\end{array}$ & $\begin{array}{c}14.35 \\
(0.01-468.8)\end{array}$ & $<0.001^{\mathrm{b} *}$ \\
\hline $\begin{array}{l}\text { Time of occurrence of VA event (\%): } \\
-6 \text { months } \\
-1 \text { year }\end{array}$ & & & $\begin{array}{l}71.4 \% \\
28.6 \%\end{array}$ & ns \\
\hline
\end{tabular}

Age and peak troponin I levels are shown as median (min-max); a - comparison of control vs VA ${ }^{+}$patients; b - comparison of VA ${ }^{+}$vs VA ${ }^{-}$patients;

* statistically significant differences; ns - not significant; MI - myocardial infarction; VA - ventricular arrhythmia; SCD - sudden cardiac death. 
Table 3. Case-control study comparing minor allele frequencies between healthy controls and VA+ MI patients

\begin{tabular}{|c|c|c|c|c|}
\hline SNP (minor allele) & Healthy controls (141) & MI patients $\mathrm{VA}^{+}(70)$ & $p$-value & OR $(95 \% \mathrm{Cl})$ \\
\hline SCN5A rs11708996 (C) & 0.15 & 0.27 & $0.001^{*}$ & $\begin{array}{c}2.18 \\
(1.33-3.60)\end{array}$ \\
\hline SCN10A rs10428132 (T) & 0.10 & 0.21 & $0.001^{*}$ & $\begin{array}{c}2.46 \\
(1.39-4.36)\end{array}$ \\
\hline HEY2 rs9388451 (C) & 0.32 & 0.39 & 0.07 & $\begin{array}{c}1.36 \\
(0.89-2.07)\end{array}$ \\
\hline PITX2 rs2200733 (T) & 0.26 & 0.25 & 0.47 & $\begin{array}{c}0.95 \\
(0.59-1.52)\end{array}$ \\
\hline
\end{tabular}

Allelic data is presented as proportions; ${ }^{*}$ statistically significant differences; MI - myocardial infarction; SNP - single nucleotide polymorphism; VA - ventricular arrhythmia; OR - odds ratio; $95 \% \mathrm{Cl}$ - 95\% confidence interval.

Table 4. Genotypic distributions of rs11708996 and rs10428132 in controls and in VA+ MI patients in crude and adjusted analyses under different inheritance models

\begin{tabular}{|c|c|c|c|c|c|c|c|c|}
\hline \multirow{2}{*}{ SNP } & \multirow{2}{*}{$\begin{array}{l}\text { Inheritance } \\
\text { model }\end{array}$} & \multirow{2}{*}{ Genotypes } & \multirow{2}{*}{ Controls n (\%) } & \multirow{2}{*}{$\begin{array}{c}\mathrm{VA}^{+} \mathrm{MI} \\
\text { patients } \\
\mathrm{n}(\%)\end{array}$} & \multicolumn{2}{|c|}{ Crude analysis } & \multicolumn{2}{|c|}{$\begin{array}{l}\text { Adjusted analysis } \\
\text { (by age and gender) }\end{array}$} \\
\hline & & & & & $\begin{array}{c}\text { OR } \\
(95 \% \mathrm{Cl})\end{array}$ & $p$-value & $\begin{array}{c}\text { OR } \\
(95 \% \mathrm{Cl})\end{array}$ & $\mathrm{p}$-value \\
\hline \multirow{5}{*}{$\begin{array}{l}\text { rs11708996 } \\
(S C N 5 A)\end{array}$} & \multirow{3}{*}{ codominant } & $\mathrm{G} / \mathrm{G}$ & $103(73)$ & $42(60)$ & 1.00 & \multirow{3}{*}{$0.003^{*}$} & 1.00 & \multirow{3}{*}{$<0.001^{*}$} \\
\hline & & $\mathrm{G} / \mathrm{C}$ & $35(24.8)$ & $18(25.7)$ & $\begin{array}{c}1.26 \\
(0.64-2.47)\end{array}$ & & $\begin{array}{c}1.23 \\
(0.55-2.75)\end{array}$ & \\
\hline & & $\mathrm{C} / \mathrm{C}$ & $3(2.1)$ & $10(14.3)$ & $\begin{array}{c}8.17 \\
(2.14-31.19)\end{array}$ & & $\begin{array}{c}19.23 \\
(3.31-111.85)\end{array}$ & \\
\hline & dominant & $\mathrm{G} / \mathrm{G}$ vs $\mathrm{G} / \mathrm{C}-\mathrm{C} / \mathrm{C}$ & 103 vs 38 & 42 vs 28 & $\begin{array}{c}1.81 \\
(0.99-3.31)\end{array}$ & 0.057 & $\begin{array}{c}2.01 \\
(0.97-4.17)\end{array}$ & 0.058 \\
\hline & recessive & G/G-G/C vs C/C & 138 vs 3 & 60 vs 10 & $\begin{array}{c}7.67 \\
(2.04-28.85)\end{array}$ & $<0.001^{*}$ & $\begin{array}{c}18.16 \\
(3.17-103.97)\end{array}$ & $<0.001^{*}$ \\
\hline \multirow{5}{*}{$\begin{array}{l}\text { rs10428132 } \\
\text { (SCN1OA) }\end{array}$} & \multirow{3}{*}{ codominant } & $\mathrm{G} / \mathrm{G}$ & $117(83)$ & $46(65.7)$ & 1.00 & \multirow{3}{*}{$0.016^{*}$} & 1.00 & \multirow{3}{*}{$0.038^{*}$} \\
\hline & & $\mathrm{G} / \mathrm{T}$ & $21(14.9)$ & $19(27.1)$ & $\begin{array}{c}2.30 \\
(1.13-4.67)\end{array}$ & & $\begin{array}{c}2.84 \\
(1.20-6.71)\end{array}$ & \\
\hline & & $T / T$ & $3(2.1)$ & $5(7.1)$ & $\begin{array}{c}4.24 \\
(0.97-18.46)\end{array}$ & & $\begin{array}{c}2.51 \\
(0.47-13.52)\end{array}$ & \\
\hline & dominant & G/G vs G/T-T/T & 117 vs 24 & 46 vs 24 & $\begin{array}{c}2.54 \\
(1.31-4.92)\end{array}$ & $0.005^{*}$ & $\begin{array}{c}2.78 \\
(1.26-6.16)\end{array}$ & $0.011^{*}$ \\
\hline & recessive & G/G-G/T vs T/T & 183 vs 3 & 65 vs 5 & $\begin{array}{c}3.54 \\
(0.82-15.26)\end{array}$ & 0.084 & $\begin{array}{c}2.78 \\
(1.26-6.16)\end{array}$ & 0.39 \\
\hline
\end{tabular}

* statistically significant differences; MI - myocardial infarction; SNP - single nucleotide polymorphism; VA - ventricular arrhythmia; OR - odds ratio; 95\% Cl-95\% confidence interval.

to present VA than those without ST elevation (NSTEMI), especially in the first 6 months after the event. The mean peak of troponin I levels was significantly more elevated in $\mathrm{VA}^{+}$patients. Coronary angiograms showed one-vessel disease in the vast majority of patients $(73.47 \%)$, and no significant differences between the 2 groups were found in this respect.

\section{Genetic analysis}

The genotype distribution in the groups examined was concordant with the Hardy-Weinberg equilibrium (all p > 0.05). Table 3 shows the results of HEY2, SCN5A, SCN10A and PITX2 allele frequencies. The minor alleles of SCN5A (rs11708996, G > C) and SCN10A (rs10428132, $\mathrm{G}>\mathrm{T}$ ) significantly increased the risk of arrhythmia in patients with MI (SCN5A: p =0.001; OR $=2.18$ and $S C N 10 A: \mathrm{p}=0.001 ; \mathrm{OR}=2.46)$. There was no significant relationship between HEY2 (rs9388451, T > C) and PITX2 (rs2200733, C > T) SNPs and the risk of developing VA.

\section{Genotype distributions}

Genotype distributions for the 2 SNPs that showed significant association are described in Table 4. Genotype frequencies were compared using crude analyses and analyses adjusted by age and gender, under different inheritance models.

The results of the crude analyses revealed that the $\mathrm{CC}$ genotype of SCN5A rs11708996 is significantly associated with the occurrence of arrhythmia under the recessive $(\mathrm{p}<0.001 ; \mathrm{OR}=7.67)$ and codominant $(\mathrm{p}=0.003$; $\mathrm{OR}=8.17$ ) models. The TT genotype of SCN10A rs10428132 
Table 5. Association analyses using allelic frequencies of $\mathrm{VA}^{+}$and $\mathrm{VA}^{-} \mathrm{MI}$ patients

\begin{tabular}{|c|c|c|c|c|}
\hline SNP (minor allele) & $\mathrm{VA}^{+} \mathrm{MI}$ patients (70) & $\mathrm{VA}^{-}$MI patients (258) & $\mathrm{p}$-value & OR $(95 \% \mathrm{Cl})$ \\
\hline SCN5A rs11708996 (C) & 0.27 & 0.19 & $0.019^{*}$ & $\begin{array}{c}1.58 \\
(1.03-2.44)\end{array}$ \\
\hline SCN10A rs10428132 (T) & 0.21 & 0.12 & $0.006^{*}$ & $\begin{array}{c}1.94 \\
(1.19-3.17)\end{array}$ \\
\hline HEY2 rs9388451 (C) & 0.39 & 0.31 & 0.056 & $\begin{array}{c}1.39 \\
(0.94-2.05)\end{array}$ \\
\hline PITX2 rs2200733 (T) & 0.25 & 0.23 & 0.29 & $\begin{array}{c}1.12 \\
(0.72-1.73)\end{array}$ \\
\hline
\end{tabular}

* statistically significant differences; MI - myocardial infarction; SNP - single nucleotide polymorphism; VA - ventricular arrhythmia; OR - odds ratio; 95\% Cl - 95\% confidence interval.

showed an association with the arrhythmic group under the codominant $(\mathrm{p}=0.016 ; \mathrm{OR}=2.30)$ and the dominant ( $\mathrm{p}=0.005$; OR $=2.54)$ models. The adjusted analyses reinforce these associations (Table 4).

Allelic associations of the 4 SNPs between the 2 cohorts of $\mathrm{MI}$ patients $\left(\mathrm{VA}^{+}\right.$and $\mathrm{VA}^{-}$) revealed significant differences between the proportions of the C allele of SCN5A $\operatorname{rs} 11708996(\mathrm{p}=0.019 ; \mathrm{OR}=1.58)$ and the $\mathrm{T}$ allele of $S C N 10 A$ rs10428132 ( $\mathrm{p}=0.006 ; \mathrm{OR}=1.94)$. In fact, the frequencies of these 2 alleles are increased in the group of $\mathrm{VA}^{+}$patients (Table 5). Subsequent analyses of the genotypic associations showed no significant differences between the 2 groups.

\section{Discussion}

Many studies have suggested that the risk of fatal arrhythmias may be modulated by genetically determined variants in several genes, especially those responsible for the expression of ion channels. ${ }^{18}$ In this work, we selected 4 SNPs that are reported to be associated with certain forms of cardiac death. We investigated whether any of these genetic markers are of predictive value in assessing the risk of developing arrhythmia and SCD in patients with MI. Three of them were reported to have a strong association with BrS in a GWAS that located them in the $S C N 5 A$, $S C N 10 A$ and HEY2 genes. ${ }^{13}$ The $4^{\text {th }}$ SNP is located near the PITX2 gene and was reported to be strongly associated with lone atrial fibrillation. ${ }^{12}$

Our results showed that 2 of the 4 SNPs are significantly associated with the risk of developing VA in the context of MI. The first association is observed with rs11708996, located in intron 21 of the SCN5A gene. The C allele frequencies are significantly higher in $\mathrm{VA}^{+} \mathrm{MI}$ patients compared to healthy controls and $\mathrm{VA}^{-} \mathrm{MI}$ cases. A previous study showed that rs11708996 is associated with significant electrocardiographic changes in ST elevation, PR interval and QRS duration, which may explain the effect in arrhythmic patients. ${ }^{19}$ The $S C N 5 A$ gene encodes the alpha subunit of the cardiac sodium channels responsible for the rapid upstroke of cardiac action potential, and plays a central role in the excitability of myocardial cells. ${ }^{20}$
Mutations in SCN5A are associated with a broad spectrum of inherited cardiac arrhythmias, such as long QT syndrome type III, ${ }^{21} \mathrm{BrS},{ }^{22}$ idiopathic $\mathrm{VF},{ }^{23}$ sudden infant death syndrome, ${ }^{24}$ and cardiac conduction defects. ${ }^{25}$ Many studies have found associations between common polymorphisms in the SCN5A gene and SCD in acquired heart diseases ${ }^{26,27}$; however, a minority focused on VA and SCD in the context of MI.

Investigations performed in a very heterogeneous cohort of cardiac death victims showed that, compared to controls, the CC genotype of the SCN5A rs117205200 polymorphism was significantly associated with ischemic heart disease $(\mathrm{p}=0.012 ; \mathrm{OR}=1.45) .{ }^{28}$ Other investigations screened the $S C N 5 A$ gene in cases of sudden cardiac arrest associated with $\mathrm{CAD}$, and found that the proportion of synonymous and non-synonymous nucleotide changes was higher in the case subjects than in the controls. However, none of these SNPs had an association with the disease. ${ }^{29}$ These 2 studies prove the effect of SCN5A gene polymorphisms in acquired heart rhythm disorder.

The $2^{\text {nd }}$ association is found with rs10428132, located in intron 14 of the SCN1OA gene, which is adjacent to SCN5A on chromosome 3p21-22. Recent studies have shown that the sodium channel isoform Nav1.8 coded by SCN1OA, besides being expressed in cardiac neurons, ${ }^{30}$ is expressed in the working myocardium and the specialized conduction system, ${ }^{31}$ indicating a possible role for Nav1.8 in cardiac electrical function. However, any genetic implication of this protein in SCD remains undetected, probably due to the fact that the Nav1.8 protein is expressed more in the central and peripheral nervous systems than in the heart. That is why the SCN10A gene is not yet included in the panel of arrhythmia and SCD diagnosis in the vast majority of cardiogenetic centers. ${ }^{14}$ Our result concerning the association of the SCN1OA gene polymorphism with arrhythmia constitutes a novel element that could help in the diagnosis of SCD based on this gene and Nav1.8 protein.

Furthermore, the SNP rs6801957, which is in high linkage disequilibrium $\left(r^{2}=0.97\right)$ with $r s 10428132$, has been reported to alter a highly conserved nucleotide within a consensus T-box-binding site (TBX5 and TBX3), which functionally affects the SCN5A/SCN1OA enhancer. ${ }^{32}$ 
TBX5 drives $S C N 5 A$ expression to regulate the functioning of the cardiac conduction system. ${ }^{33}$ Further studies are required to determine whether the effects of rs10428132 on conduction and arrhythmia are mediated through regulation of $S C N 5 A, S C N 10 A$ or both.

In this paper, $21.3 \%$ of MI patients developed VA after a 1 year follow-up. These results are consistent with those found in a large cohort of MI patients, showing that early arrhythmic complications occur in nearly $9.3 \%$ of patients with MI, and in $22.3 \%$ of patients after a follow-up of 5 years. ${ }^{5}$ The results of the association analyses of the 2 SNPs in SCN5A and SCN1OA with MI VA ${ }^{+}$patients showed strong $\mathrm{p}$-values and OR when compared to healthy controls. This could indicate that the population of MI $\mathrm{VA}^{-}$patients is still at risk of developing VA.

Genetic similarities between VA during MI and BrS found for the first time in this paper may be explained by the fact that both clinical entities are the result of similar electrophysiological substrates, and both can result in SCD. In addition, studies have shown that ST segment elevation during acute MI recapitulates features of $\mathrm{BrS}$ and may be the result of closely coupled phase 2 reentrant extrasystoles. ${ }^{10}$

Regarding HEY2 polymorphisms, rs9388451 showed no association with VA patients $(\mathrm{p}=0.07)$. Bezzina et al. were the first to report association between rs9388451 and BrS. ${ }^{13}$ The risk allele of this SNP has also been found in association with cardiac arrest/VA in the larger UK Biobank population, indicating a possible pathological role of this allele in cardiac arrhythmia. ${ }^{19}$ The effect of this SNP on cardiac conduction may be explained by its location near the HEY2 gene, encoding a transcriptional repressor that is important in the development of the cardiovascular system. ${ }^{34}$ Experiments in HEY2 knock-out embryos showed abnormal right ventricle morphology and a spectrum of postnatal cardiomyopathies. ${ }^{35}$ Our results concerning the lack of association for this SNP are near the threshold of significance $(p=0.05)$. This may be due, first, to the small number of $\mathrm{MI} \mathrm{VA}{ }^{+}$patients and, second, to the fact that the MI $\mathrm{VA}^{-}$population is still at risk of developing VA.

As for rs2200733, it also showed no association with the MI VA+ patients compared to the healthy controls $(\mathrm{p}=0.47)$. This SNP is located $150 \mathrm{~kb}$ upstream of the PITX2 gene that codes for transcription factors playing an important role in the embryonic development of heart left-right symmetry. ${ }^{36}$ PITX2 is also implicated in the development of the pulmonary vein myocardium, which is a major source of atrial arrhythmogenesis. ${ }^{37}$ The rs2200733 SNP is well-established to be at risk of developing $\mathrm{AF}^{38}$ and SCD. ${ }^{39}$ The study by Lahtinen et al. supports a joint genetic pathway between AF and VF, or at least abnormal cardiac function. ${ }^{39}$ No association between rs2200733 and the risk of VA was found in the Tunisian population (this study). Our results are in agreement with a case-control study that found no association between 24 common genetic variants, including rs2200733, related to AF and the risk of VF in the setting of first STEMI. ${ }^{40}$
Our results support the idea that cardiac electrical abnormalities may be the result of variations in genes coding ion channels. On the other hand, our study shows that SNPs in genes involved in embryonic cardiogenesis, previously associated with congenital heart rhythm diseases, are not associated with acquired heart rhythm disorders.

\section{Conclusions}

The study was conducted on a small sample size, due to the very critical nature of the clinical situation. The inclusion criteria were highly restricted in an effort to maintain the homogeneity of the cohort. On the other hand, the practical and clinical significance of the associated polymorphisms in SCN5A and SCN1OA remains an open question. These observations need to be further confirmed by a larger number of $\mathrm{VA}^{+}$patients and deeper genetic explorations that can be correlated to clinical characteristics.

The major strength of this study is the originality of the concept and the results. In fact, we are the first to carry out an association study of 4 polymorphisms, previously associated to $\mathrm{BrS}$ and $\mathrm{AF}$, with $\mathrm{VA}$ in the context of MI. We found that SCN5A rs11708996 and SCN10A rs10428132 are significantly associated with the risk of VA in MI patients. In addition, we demonstrated novel genetic similarities between VA in acquired heart disease and $\mathrm{BrS}$. Based on these novel findings, we hypothesize that variations in genes coding for cardiac ion channels or modulating their expression, which are currently used to stratify arrhythmic risk in patients with inherited syndromes of SCD, may also be associated with the occurrence of VA during MI. Our results may enable us to distinguish patients who are genetically susceptible to developing VA and SCD. This could make them more aware of their situation and could orient their clinicians toward better treatments. In addition, further study of the functional consequences of these variants on cardiac electrophysiology may lead to important advances in our understanding of the mechanisms underlying SCD and could ultimately lead to novel therapeutic approaches.

\section{ORCID iDs}

Hajer Foddha (D) https://orcid.org/0000-0003-1490-3772 Nadia Bouzidi (D) https://orcid.org/0000-0003-3722-7279 Abdelhak Foddha (1) https://orcid.org/0000-0002-7325-9158 Saoussen Chouchene (D) https://orcid.org/0000-0003-1428-9856 Rahma Touhami (D) https://orcid.org/0000-0002-6558-4292 Nadia Leban (1D) https://orcid.org/0000-0002-5913-7795 Mohamed Faouzi Maatoug (D) https://orcid.org/0000-0003-1062-6712 Habib Gamra (D) https://orcid.org/0000-0001-8758-5766 Salima Ferchichi (D) https://orcid.org/0000-0002-1532-066X Jemni Ben Chibani (i) https://orcid.org/0000-0003-3575-610X Amel Haj Khelil (D) https://orcid.org/0000-0001-5404-2116

\section{References}

1. Priori SG, Aliot E, Blomstrom-Lundqvist C, et al. Task Force on Sudden Cardiac Death, European Society of Cardiology. Summary of recommendations. Ital Heart J Suppl. 2002;3(10):1051-1065. 
2. Henkel DM, Witt BJ, Gersh BJ, et al. Ventricular arrhythmias after acute myocardial infarction: A 20-year community study. Am Heart J. 2006;151(4):806-812.

3. Khairy $P$, Thibault $B$, Talajic M, et al. Prognostic significance of ventricular arrhythmias post-myocardial infarction. Can J Cardiol. 2003; 19(12):1393-1404.

4. Spooner PM, Albert C, Benjamin EJ, et al. Sudden cardiac death, genes, and arrhythmogenesis: Consideration of new population and mechanistic approaches from a National Heart, Lung, and Blood Institute workshop, Part II. Circulation. 2001;103(20):2447-2452.

5. Jabbari R, Engstrom T, Glinge $C$, et al. Incidence and risk factors of ventricular fibrillation before primary angioplasty in patients with first ST-elevation myocardial infarction: A nationwide study in Denmark. J Am Heart Assoc. 2015;4(1):e001399.

6. Maekawa K, Saito Y, Ozawa S, et al. Genetic polymorphisms and haplotypes of the human cardiac sodium channel alpha subunit gene (SCN5A) in Japanese and their association with arrhythmia. Ann Hum Genet. 2005;69(Pt 4):413-428.

7. Hu D, Viskin S, Oliva A, et al. Genetic predisposition and cellular basis for ischemia-induced ST-segment changes and arrhythmias. J Electrocardiol. 2007;40(6 Suppl):S26-S29.

8. Brugada P, Brugada J. Right bundle branch block, persistent ST segment elevation and sudden cardiac death: A distinct clinical and electrocardiographic syndrome. A multicenter report. J Am Coll Cardiol. 1992;20(6):1391-1396.

9. Indik JH, Ott P, Butman SM. Syncope with ST-segment abnormalities resembling Brugada syndrome due to reversible myocardial ischemia. Pacing Clin Electrophysiol. 2002;25(8):1270-1273.

10. Di Diego JM, Fish JM, Antzelevitch C. Brugada syndrome and ischemia-induced ST-segment elevation: Similarities and differences. J Electrocardiol. 2005;38(4 Suppl):14-17.

11. Benjamin EJ, Wolf PA, D'Agostino RB, Silbershatz $H$, Kannel WB, Levy D. Impact of atrial fibrillation on the risk of death: The Framingham Heart Study. Circulation. 1998;98(10):946-952.

12. Gudbjartsson DF, Arnar DO, Helgadottir A, et al. Variants conferring risk of atrial fibrillation on chromosome 4q25. Nature. 2007;448(7151): 353-357.

13. Bezzina CR, Barc J, Mizusawa Y, et al. Common variants at SCN5ASCN10A and HEY2 are associated with Brugada syndrome, a rare disease with high risk of sudden cardiac death. Nat Genet. 2013;45(9): 1044-1049.

14. Monasky MM, Micaglio E, Vicedomini G, et al. Comparable clinical characteristics in Brugada syndrome patients harboring SCN5A or novel SCN10A variants. Europace. 2019;21(10):1550-1558.

15. Neubauer J, Wang Z, Rougier JS, et al. Functional characterization of a novel SCN5A variant associated with long QT syndrome and sudden cardiac death. Int J Legal Med. 2019;133(6):1733-1742.

16. Nunez-Gil IJ, Riha H, Ramakrishna H. Review of the 2017 European Society of Cardiology's Guidelines for the Management of Acute Myocardial Infarction in Patients Presenting with ST-Segment Elevation and Focused Update on Dual Antiplatelet Therapy in Coronary Artery Disease Developed in Collaboration with the European Association for Cardio-Thoracic Surgery. J Cardiothorac Vasc Anesth. 2019;33(8):2334-2343.

17. Sole X, Guino E, Valls J, Iniesta R, Moreno V. SNPStats: A web tool for the analysis of association studies. Bioinformatics. 2006;22(15): 1928-1929.

18. Nattel S, Frelin Y, Gaborit N, Louault C, Demolombe S. Ion-channel mRNA-expression profiling: Insights into cardiac remodeling and arrhythmic substrates. J Mol Cell Cardiol. 2010;48(1):96-105.

19. Andreasen L, Ghouse J, Skov MW, et al. Brugada syndrome-associated genetic loci are associated with J-point elevation and an increased risk of cardiac arrest. Front Physiol. 2018;9:894.
20. Balser JR. Structure and function of the cardiac sodium channels. Cardiovasc Res. 1999;42(2):327-338.

21. Wang Q, Shen J, Splawski I, et al. SCN5A mutations associated with an inherited cardiac arrhythmia, long QT syndrome. Cell. 1995;80(5): 805-811.

22. Chen Q, Kirsch GE, Zhang D, et al. Genetic basis and molecular mechanism for idiopathic ventricular fibrillation. Nature. 1998;392(6673): 293-296.

23. Akai J, Makita N, Sakurada H, et al. A novel SCN5A mutation associated with idiopathic ventricular fibrillation without typical ECG findings of Brugada syndrome. FEBS Lett. 2000;479(1-2):29-34.

24. Ackerman MJ, Siu BL, Sturner WQ, et al. Postmortem molecular analysis of SCN5A defects in sudden infant death syndrome. JAMA. 2001; 286(18):2264-2269.

25. Schott JJ, Alshinawi C, Kyndt F, et al. Cardiac conduction defects associate with mutations in SCN5A. Nat Genet. 1999;23(1):20-21.

26. Burke A, Creighton W, Mont E, et al. Role of SCN5A Y1102 polymorphism in sudden cardiac death in blacks. Circulation. 2005;112(6): 798-802.

27. Splawski I, Timothy KW, Tateyama M, et al. Variant of SCN5A sodium channel implicated in risk of cardiac arrhythmia. Science. 2002; 297(5585):1333-1336.

28. Marcsa B, Denes R, Voros K, et al. A common polymorphism of the human cardiac sodium channel alpha subunit (SCN5A) gene is associated with sudden cardiac death in chronic ischemic heart disease. PLoS One. 2015;10(7):e0132137.

29. Stecker EC, Sono M, Wallace E, Gunson K, Jui J, Chugh SS. Allelic variants of SCN5A and risk of sudden cardiac arrest in patients with coronary artery disease. Heart Rhythm. 2006;3(6):697-700.

30. Verkerk AO, Remme CA, Schumacher CA, et al. Functional Nav1.8 channels in intracardiac neurons: The link between SCN10A and cardiac electrophysiology. Circ Res. 2012;111(3):333-343.

31. Yang T, Atack TC, Stroud DM, Zhang W, Hall L, Roden DM. Blocking Scn10a channels in heart reduces late sodium current and is antiarrhythmic. Circ Res. 2012;111(3):322-332.

32. van den Boogaard M, Wong LY, Tessadori F, et al. Genetic variation in T-box binding element functionally affects SCN5A/SCN10A enhancer. J Clin Invest. 2012;122(7):2519-2530.

33. Arnolds DE, Liu F, Fahrenbach JP, et al. TBX5 drives Scn5a expression to regulate cardiac conduction system function. J Clin Invest. 2012; 122(7):2509-2518.

34. Fischer A, Gessler M. Hey genes in cardiovascular development. Trends Cardiovasc Med. 2003;13(6):221-226.

35. Sakata Y, Kamei CN, Nakagami H, Bronson R, Liao JK, Chin MT. Ventricular septal defect and cardiomyopathy in mice lacking the transcription factor CHF1/Hey2. Proc Natl Acad Sci U S A. 2002;99(25):16197-16202.

36. Franco D, Campione M. The role of Pitx2 during cardiac development: Linking left-right signaling and congenital heart diseases. Trends Cardiovasc Med. 2003;13(4):157-163.

37. Mommersteeg MT, Brown NA, Prall OW, et al. Pitx2c and Nkx2-5 are required for the formation and identity of the pulmonary myocardium. Circ Res. 2007;101(9):902-909.

38. Olesen MS, Nielsen MW, Haunso S, Svendsen JH. Atrial fibrillation: The role of common and rare genetic variants. Eur J Hum Genet. 2014; 22(3):297-306.

39. Lahtinen AM, Noseworthy PA, Havulinna AS, et al. Common genetic variants associated with sudden cardiac death: The FinSCDgen study. PloS One. 2012;7(7):e41675.

40. Jabbari R, Glinge C, Jabbari J, et al. A common variant in SCN5A and the risk of ventricular fibrillation caused by first ST-segment elevation myocardial infarction. PLoS One. 2017;12(1):e0170193. 